\title{
Images in Anesthesia
}

\section{The role of transesophageal echocardiography in coronary artery fistula surgery}

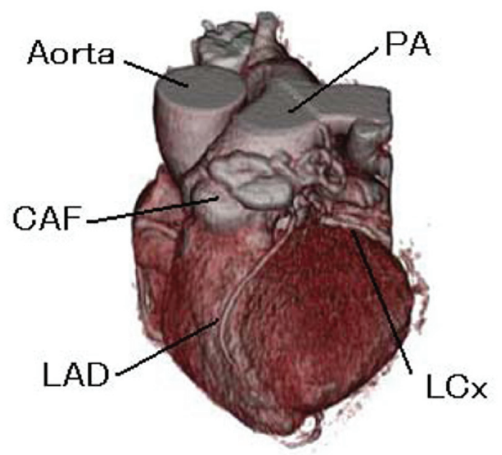

A

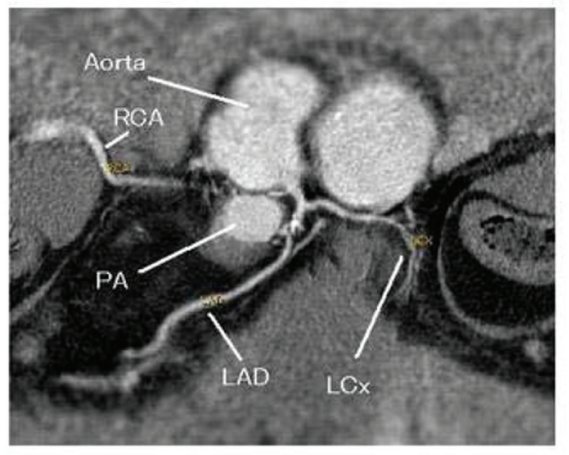

B

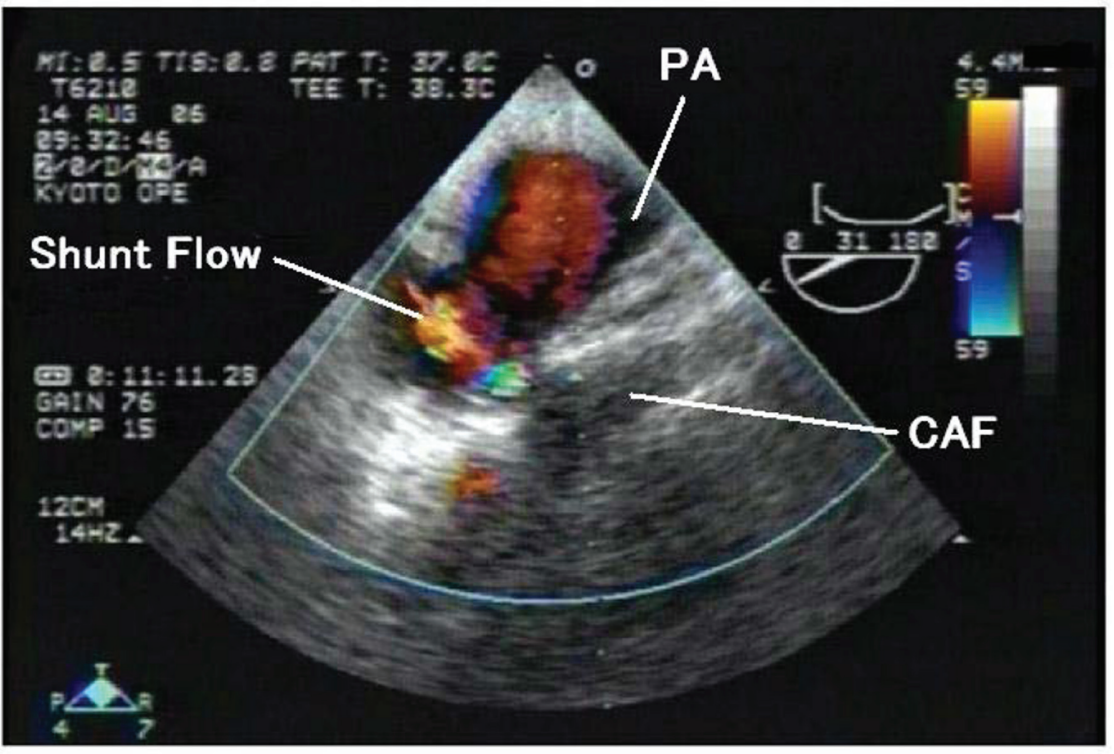

C

FIGURE The coronary artery fistula, with the aneurysmal changes arising from the left anterior descending coronary artery, are shown. A) Preoperative, three-dimensional, computed tomography with volume-rendering image; B) Preoperative, computed tomography with multi-planar reformation image; C) Intraoperative, transesophageal echocardiogram, mid-esophageal, ascending aortic, short axis view. CAF = coronary artery fistula with aneurysm; PA = pulmonary artery; LAD = left anterior descending coronary artery; LCx, = left circumflex coronary artery; RCA = right coronary artery. 
$\mathrm{C}$

ORONARY artery fistulae (CAF), which may be either congenital or acquired, are observed in $0.2-5 \%$ of coronary angiograms. Coronary artery fistulae are frequently arterioluminal; but, occasionally, these lesions are aneurysmal. Coronary artery fistulae involve the right, the left, or both coronary arteries in approximately $60 \%, 30 \%$, or $10 \%$ of cases, respectively. These fistulae may drain into the right ventricle $(41 \%$ of cases), the right atrium (26\% of cases), the pulmonary artery ( $17 \%$ of cases), or the coronary sinus $(7 \%$ of cases). Patients with CAF may develop symptoms of congestive heart failure, either from left-to-right shunt, or from myocardial ischemia secondary to coronary artery steal. The frequency of symptoms and the incidence of complications of CAF, which increase with age, include thromboembolism, congestive heart failure, cardiac arrhythmias, endocarditis, and, rarely, rupture of the fistula. Thus, closure of the fistula is recommended, even in the absence of symptoms. ${ }^{1,2}$

A 73-yr-old man presented with a ten-year history of dyspnea on exertion. Preoperative computed tomography indicated a CAF with an aneurysm draining into the main pulmonary artery (Figure, Panels A and B). Intraoperative, transesophageal echocardiography confirmed CAF, accompanied with a $21-\mathrm{mm}$ aneurysm draining into the main pulmonary artery. Turbulent flow created a mosaic echo in the main pulmonary artery as seen on the mid-esophageal, ascending aortic, short axis view (Figure, Panel C). Surgery was performed to stop the shunt by closing the origin and the drainage sites of the CAF. Turbulent flow in the main pulmonary artery decreased after weaning the patient from cardiopulmonary bypass. The patient was discharged with no complications. This case highlights the value of intraoperative, transesophageal echocardiography in the diagnosis and management of CAF.

Masayuki Shibasaki MD

Yasufumi Nakajima MD PhD

Kyoto Prefectural University of Medicine, Kyoto, Japan

E-mail: nakajima@koto.kpu-m.ac.jp

Accepted for publication January 7, 2008.
References

1 Cheung DL, Au WK, Cheung HH, Chiu CS, Lee WT. Coronary artery fistulas: long-term results of surgical correction. Ann Thorac Surg 2001; 71: 190-5.

2 David AM, Bernard JG, Eugene B. Coronary artery ectasia and aneurysms. In: Zipes DP, Libby P, Bonow RO, Braunwald E (Eds). Braunwald's Heart Disease: A Textbook of Cardiovascular Medicine, $7^{\text {th }}$ ed. Philadelphia: Elsevier Saunders; 2005: 1290. 